\title{
Welcome to a New Section in the JNMT: Educators' Forum
}

\author{
Jennifer L. Prekeges, CNMT, FSNMMI-TS \\ Nuclear Medicine Technology Program, Bellevue College, Bellevue, Washington
}

A $\mathrm{S}$ an educator of nuclear medicine technologists, I am a rare breed. There are only a few hundred of us in the United States, and we do not get many opportunities to meet with and learn from one another. The SNMMI annual meeting is our one chance each year to come together, share ideas, and compare notes. The Educators' Forum sessions at the annual meeting are always of great interest to me, and I would love to see them shared in additional formats. At the sessions, my fellow educators discuss their many interesting and innovative ideas about nuclear medicine technologist education. But as things currently stand, I can benefit from those discussions only if I am present at a session and then only to the extent that I can remember them afterward.

I was therefore happy to hear that Kathy Thomas, the new editor of JNMT, wanted to dedicate a section of the journal to articles of interest to educators and students. There is no more logical place than JNMT for articles about nuclear medicine education, but they did not fit well into previously existing sections. Adding this section will enhance the journal's value to this audience.

The editorial vision is to have an Educators' Forum section in each issue of the journal, including several offerings. A lead article on a subject of interest to educators might be paired with a "how-to" companion piece. Results of a survey of educators might be included, as well as a textbook review or opinion piece and perhaps a student perspective. We hope that these articles will be of interest not only to educators but also to technologist students and the more general audience.
Each issue's Educators' Forum will be put together by the JNMT editors with an eye to creating a cohesive and interesting section. The editors will need the assistance of the educator community to put together the section each quarter. Our starting point will be the educator sessions at the SNMMI annual meetings; there are usually 2 or 3 presentations each year that would translate well into articles. We will need a good pool of writers and peer reviewers; we will need ideas for the section's theme for each issue; and we will need responses from all educators to short surveys to gauge the value of various topics to the nuclear medicine educator/student community.

For our first Educators' Forum, we have an article by Cybil Nielsen from Indiana University on how she engages her students in research. She presented a session on this topic at the 2017 annual meeting, and those of us who were present were fascinated with her approach and interested in implementing it in our own programs. Publication of this article will be very useful to me, and I hope my fellow educators will be interested as well.

As I noted in my opening paragraph, the nuclear medicine educator community is a small one. Dedicating a section of JNMT to our needs is a significant step. I am very grateful to Kathy Thomas for taking this step and happy to have a part in bringing it to fruition. We look forward to providing an interesting and informative Educators' Forum in each issue of JNMT.

Received Nov. 7, 2017; revision accepted Dec. 1, 2017.

For correspondence or reprints contact: Jennifer L. Prekeges, CNMT, FSNMMI-TS, Bellevue College, 3000 Landerholm Circle S.E., Bellevue, WA 98007.

E-mail: jennifer.prekeges@bellevuecollege.edu

Published online Dec. 22, 2017.

COPYRIGHT (c) 2018 by the Society of Nuclear Medicine and Molecular Imaging. DOI: $10.2967 /$ jnmt.117.204982 